\title{
Sôro de leite de Petruscky-Simplificação da tecnica para preparo desse meio de cultura \\ pelo
}

\author{
DR. A. FONTES
}

(Assistente).

\section{Sérum de lait de Petruscky-Simplification de la mé= thode pour préparer ce milieu de culture. \\ par}

\section{IE DR. A. FONTES}

(Assistent).

Todo aquele que estuda o grupo coli-tifico conhece a dificuldade de obter um sôro de PETRUSCKY, que corrresponda ás condições impostas para que sirva como meio de cultura para o diagnostico diferencial dos germes daquele grupo.

Temos ultimamente usado da seguinte tecnica que facilita muitissimo o preparo do sôro de leite turnesolado.

10 tempo) - Coagulação da caseina

Para 1 liıro de leite empregar 1 c. c. de $\mathrm{H}$. Cl. puro do comercio diluido em 20 c. c. de agua.

Aquecer, em autoclave, em vapor fluente, durante 15 minutos.

Deixar esfriar.

2o tempo) - Separação da caseina.

Filtrar em papel Chardin. (Convem usar
Tout ceux qui étudient le groupe colityphique savent combien il est difficile d'obtenir un sérum de Pétruscky, sachant remplir les conditions exigées pour servir de milieu de culture au diagnostic différentiel des germes de ce groupe.

Nous avons employé dernièrement la methode suivante qui facilite beaucoup la préparation du sérum de lait tournesolé.

10) - Coagulation de la caséine.

Employer pour 1 litle de lait $1 \mathrm{cc}$ de HCL pur, dissous en 20 cc. d'eau.

Chauffer à l'autoclave, sans pression, pendant 15 minutes.

Laisser refroidir.

20)-Séparation de la caseine.

Filtrer avec du papier Chardin (Em- 
diversos filtros para acelerar a filtração).

3o tempo)-Alcalinizar muito levemente av turnesol.

40 tempo)-Aquecer em autoclave, em vapor fluente, durante 20 minutos.

50 tempo) - Resfriar.-Juntar 5\% de tintura de turnesol neutro Kahlbaum.

Si o sôro estiver com reação acida, neutralizar cuidadosamente com solução de soda (KOH) a $1 \%$.

Filtrar em vela BERKEFELD ou CHAMBERLAND sob pressão. Essa filtração pode Ser feita em vasos conjugados, dos quais um serve depois de vaso distribuidor.

Por essa tecnica suprime-se a fase mais incomoda da tecnica classica que compreende a neutralização do sôro já aquecido e filtrado em papel até que passe perfeitamente limpido e neutro, o que ás vezes só se consegue após dous ou mais aquecimento. Muito frequentemente quando se retira o sôro do autoclave, mesmo quando já ele não está mais turvo, a ação repetida do calor altera o meio amarelecendo-o, o que o torna improprio para a cultura.

Manguinhos, 23 de Agosto 1914. ployer plusieur filtres pour accélérer la filtration).

30) - Alcaliniser trés légérement au tournesol.

40)-Chauffer a l'autoclave, sans pression, pendant 20 minutes.

50)-Laisser refroidir. Ajouter $5 \%$ de teinture de tournesol neutre Kahlbaum.

Si le sérum présente une réaction acide, neutraliser soigneusement avec une solution de soude $(\mathrm{KOH})$ à $1 \%$.

Filtrer en bougie Berkefeld ou Chamberland sous pression. Cette filtration peut être fait dans des vases conjugés dont l'un sert ensuite de vase distributeur. On supprime par cette méthode la phase la plus incommode de la technique classique qui comprend la neutralisation du sérum, une fois chauffé et filtré, jusqu'á ce qu'il passe absolument limpide et neutre, ce qu'on n'obtient parfois qu'aprés deux ou trois chauffages, ou même davantage. 11 arrive souven', lorsqu'on retire le sérum, même limpide, de l'autoclave, que l'action répétée de la chaleur altére le rilieu en le jaunissant, ce que le rend impropre à la culture.

Manguinhos, 23 Aôut 1914. 